Mini Review

\title{
Gut Pacemaker Cells: the Interstitial Cells of Cajal (ICC)
}

\author{
Miyako TAKAKI ${ }^{1}$ \\ ${ }^{1}$ Department of Physiology II, Nara Medical University, 840 Shijo-cho, Kashihara 634- \\ 8521, Japan
}

\begin{abstract}
This review will focus on the pacemaker mechanisms underlying gastrointestinal autonomic rhythmicity in an attempt to elucidate the differences and similarities between the pacemaker mechanisms in the heart and gut. Interstitial cells of Cajal (ICC) form networks that are widely distributed within the submucosal (ICC-SM), intra-muscular (ICCIM, ICC-DMP) and inter-muscular layers (ICC-MY) of the gastrointestinal tract from the esophagus to the internal anal sphincter. The ICC generate spontaneously active pacemaker currents that may be recorded as plateau and slow potentials. These pacemaker currents drive the spontaneous electrical and mechanical activities of smooth muscle cells. The enteric nervous system, composed of both the myenteric (inter-muscular) plexus and the submucosal plexus, is also distributed in the gastrointestinal tract from the esophagus to the internal anal sphincter. The role of the ICC and the enteric nervous system in the integrative control of gastrointestinal function and especially of spontaneous rhythmic activity, is still unknown. Nevertheless, at least from the results presented in this review of studies of the jejunum, ileum and proximal colon of the mouse, it is convincing that the ICC drive spontaneous rhythmic motility, although a role for the enteric nervous system in the regulation of spontaneous rhythmic motility cannot be overlooked. Furthermore, intracellular $\mathrm{Ca}^{2+}$ handling has a critical role in the generation of pacemaker activity in the gut and heart, although respective players such as the $\mathrm{Ca}^{2+}$-ATPase of the sarcoplasmic reticulum (endoplasmic reticulum), $\mathrm{IP}_{3}$ receptors, ryanodine receptors and plasma membrane ion channels may have divergent roles in the $\mathrm{Ca}^{2+}$-release refilling cycles. In conclusion, intracellular $\mathrm{Ca}^{2+}$ handling plays a key role in the gut pacemaker responsible for spontaneous rhythmicity, as well as in the cardiac pacemaker responsible for spontaneous beating. Pharmacotherapeutic targeting of intracellular $\mathrm{Ca}^{2+}$ handling mechanisms may be a promising approach to the treatment and cure of gut motility dysfunction.
\end{abstract}

Key words: pacemaker, slow wave, enteric nervous system, interstitial cells of Cajal, embryonic stem cell

\section{Introduction}

The mechanisms involved in the generation of spontaneous motility in the gut have been discussed for many years. Although Hukuhara et al. (1961; 1962) have discussed "myogenic"

Correspondence to: M. Takaki, Department of Physiology II, Nara Medical University, 840 Shijo-cho, Kashihara 634-8521, Japan

Phone \& Fax: +81-744-23-4696 e-mail: mtakaki@naramed-u.ac.jp 
and "neurogenic" hypotheses, convincing evidence for either mechanism has not yet been obtained. They were however able to show that aganglionic intestinal loops still exhibited rhythmic spontaneous contractions, although intestinal intrinsic reflexes disappeared (Hukuhara et al., 1962). Within the past 10 years, there has been increasing evidence that the interstitial cells of Cajal (ICC) are the pacemaker cells of spontaneous motility in the gut (Kobayashi et al., 1996; 1995; Huizinga et al., 1995; 1997; Sanders et al., 1999). In rats and guinea pigs, Hukuhara and Neya (1968) have reported that a specific boundary region exists between the proximal and distal colon. This region has been believed to be a pacemaker region. In the rat proximal colon, indeed, rhythmic spontaneous contractions were observed (Yoneda $e t$ al., 2001). Two different frequencies of spontaneous motilities were also reported in the mouse proximal colon (Yoneda et al., 2002b; Takaki and Yoneda, 2003; Takaki et al., 2003).

Plateau potentials were recorded from ICC along the submucosal surface of the circular smooth muscle (ICC-SM) that correlate with smaller amplitude (but more frequent) circular muscle contractions in the mouse (Yoneda et al., 2002b). The plateau potentials were abolished by nifedipine $(1 \mu \mathrm{M})$ and inhibited by modulators of internal $\mathrm{Ca}^{2+}$ stores such as ryanodine (10 $\mu \mathrm{M})$, an inhibitor of $\mathrm{Ca}^{2+}-\mathrm{ATPase}$ at the internal $\mathrm{Ca}^{2+}$ stores, cyclopiazonic acid (CPA; $1 \mu \mathrm{M}$ ) (Uyama et al., 1992), caffeine $(3 \mathrm{mM})$, an intracellular $\mathrm{Ca}^{2+}$ chelator, bis-(aminophenoxy) ethane$\mathrm{N}, \mathrm{N}, \mathrm{N}$ ',N'-tetraacetic acid acetoxymethyl ester (BAPTA-AM; $20 \mu \mathrm{M}$ ) (Michelangeli et al., 1987) and an inhibitor of $\mathrm{IP}_{3}$ receptor-mediated release of $\mathrm{Ca}^{2+}$ from internal stores, 2-aminoethoxydiphenyl borate (2-APB; $10 \mu \mathrm{M}$ ) (Cui and Kanno, 1997; Maruyama et al., 1997) (Yoneda et al., 2002a).

Bursts of action potentials in circular smooth muscle cells and bursts of membrane oscillations in longitudinal smooth muscle cells correlate with larger amplitude but less frequent longitudinal and circular smooth muscle contractions in the mouse proximal colon (Yoneda $e t$ al., 2002b; Takaki and Yoneda, 2003; Takaki et al., 2003).

In the mouse proximal colon, peristalses would occur both proximally from the pacemaker region and distally towards the anus. On the basis of the frequency of these spontaneous contractions, the more frequent circular smooth muscle contractions appeared to be related to peristalsis moving proximally from the pacemaker region ("antiperistalsis"). The less frequent longitudinal and circular smooth muscle contractions appeared to be related to peristalsis distally towards the anus. Furthermore, two similar types of motilities with different frequencies have also been found in the rat colon (Plujà et al., 2000).

It is possible that under physiological conditions, more than two pacemakers could be active in the gut, whereas only a single pacemaker is likely to be active in the heart. Furthermore, in the $W / W^{\circ}$ mutant mouse ileum where the original pacemaker ICC (ICC-MY) are deficient, it was shown that they could be switched to the other type of pacemaker ICC (ICC-DMP) in which the frequency of pacemaker activity is similar to ICC-MY (Nakagawa et al., 2003). In the heart, after complete atrio-ventricular (AV) blockade, the AV node cells could act as a secondary pacemaker in which the frequency of pacemaker activity is much less than that in the sino-atrial (SA) node cells. Accordingly, there are many differences and similarities between pacemaker cells in the gut and heart.

To gain insight into pacemaker cells in the gut and heart, this review will concentrate on 


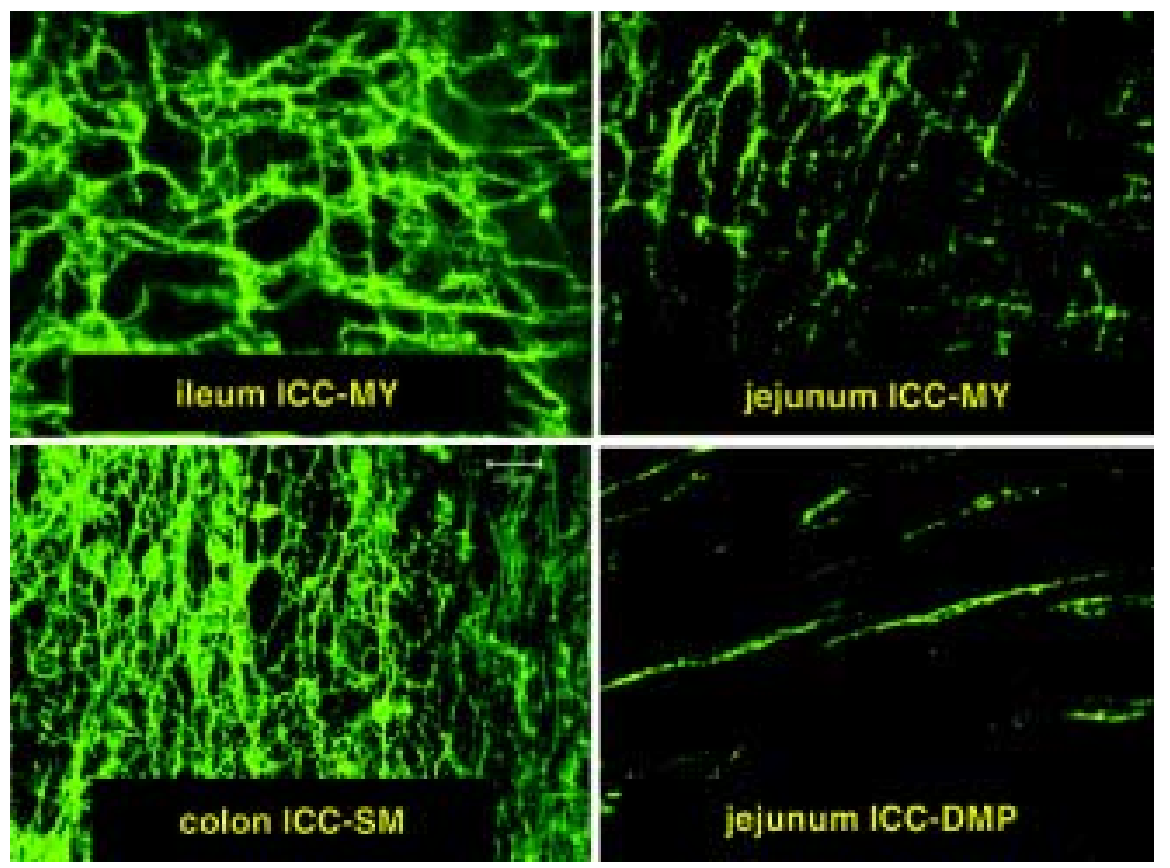

Fig. 1. Confocal images demonstrating c-Kit-like immunoreactivity stained with ACK2 in a whole mount preparation of the mouse jejunum and ileum. ICC-MY: myenteric (intermuscular) interstitial cells of Cajal (ICC). ICC-SM: submucosal ICC. ICC-DMP: deep muscular plexus ICC.

pacemaker cells in the gut wall of the mouse small intestine and proximal colon, as well as in the ES-gut which has differentiated from embryonic stem (ES) cells. It is composed of ICC cells and smooth muscle cells and could thus express spontaneously motility (Yamada et al., 2000).

\section{Classification of ICC}

Pacemaker ICC networks vary both in different regions of the gut, such as stomach, small intestine and large intestine and in different species such as mice, rats, guinea pigs and dogs. ICC networks are widely distributed within submucosal (ICC-SM), intramuscular (ICC-IM, ICCDMP) and inter-muscular layers (ICC-MY) (Sanders et al., 1999). ICC-SM are distributed on the submucosal surface of the circular muscle of the colon. ICC-MY are distributed on the myenteric region of the stomach, small intestine and colon. In the myenteric region, the myenteric neural plexus also exists. ICC-DMP are found in the deep muscular plexus region of the small intestine. ICC-IM are found intramuscularly. The classification of ICC is still confusing. I propose the following nomenclature for ICC networks for easier understanding: ICC-SM, submucosal ICC; ICC-MY, myenteric (intermuscular) ICC; ICC-IM and ICC-DMP, intramuscular ICC. Figure 1 shows confocal images of whole mount preparations of the mouse jejunum and ileum exhibiting c-Kit-like immunoreactivity stained with ACK2. 


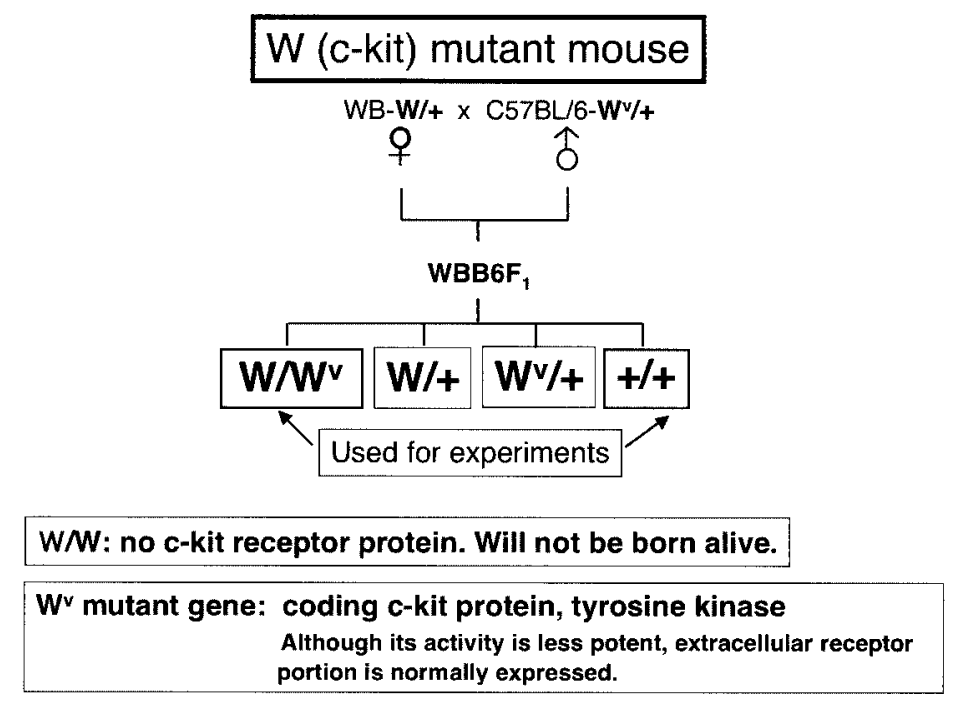

Fig. 2. Protocol for breeding $W / W^{v}$ mutant mice.

\section{ICC in W (c-kit) Mutant Mouse}

As noted in Fig. 2, $W / W$ mice do not express the c-Kit receptor protein at all and thus will not be born alive. However, those mice carrying the $W^{v}$ mutant gene which codes the c-Kit protein, normally express the extracellular receptor portion of tyrosine kinase, although with lower activity. $W / W^{v}$ mice are born alive and can be used as an ICC-deficient animal model (Huizinga et al., 1995; Ward et al., 1994), compared to the $+/+$ mouse that normally expresses the c-Kit receptor protein and thus develops ICC. In my laboratory, we were able to demonstrate ICC-MY and ICC-DMP in the jejunum and ileum of $+/+$ mice by c-Kit-LI stained with ACK2. On the other hand, in $W / W^{v}$ mice, ICC-MY immunoreactivity was invisible in the jejunum and ileum, while ICC-DMP was still present at normal levels (Nakagawa et al., 2003).

Using the apparatus as shown in Fig. 3, simultaneous recordings were made of spontaneous electrical and mechanical activities in murine $\left(+/+\right.$ and $\left.W / W^{v}\right)$ small intestine. Extracellular recording of electrical activity was performed from the serosa at the middle of a $1-2 \mathrm{~cm}$ long segment. Longitudinal smooth muscle contractions are recorded via an isometric force transducer and circular smooth muscle contractions are recorded via a pressure transducer with a hydrostatic pressure of $0-3 \mathrm{cmH}_{2} \mathrm{O}$.

In the jejunum and ileum of $+/+$ mice, regular electrical slow waves were recorded continuously, sometimes with spike potentials superimposed on the slow waves. Longitudinal and circular smooth muscle contractions were synchronous, although the amplitude of each contraction was rather variable (Fig. 4). Tetrodotoxin (TTX, $0.1 \mu \mathrm{M}$ ) (Fig. 5) or L-NAME (an NO synthase inhibitor; $10 \mu \mathrm{M}$ ) increased the amplitude of each contraction and of the slow waves, and increased the occurrence of spike potentials superimposed on the slow waves, but did not change the frequency of contractions and slow waves in either the jejunum or ileum of $+/+$ mice. These results indicate that while the amplitude of the spontaneous motility was 


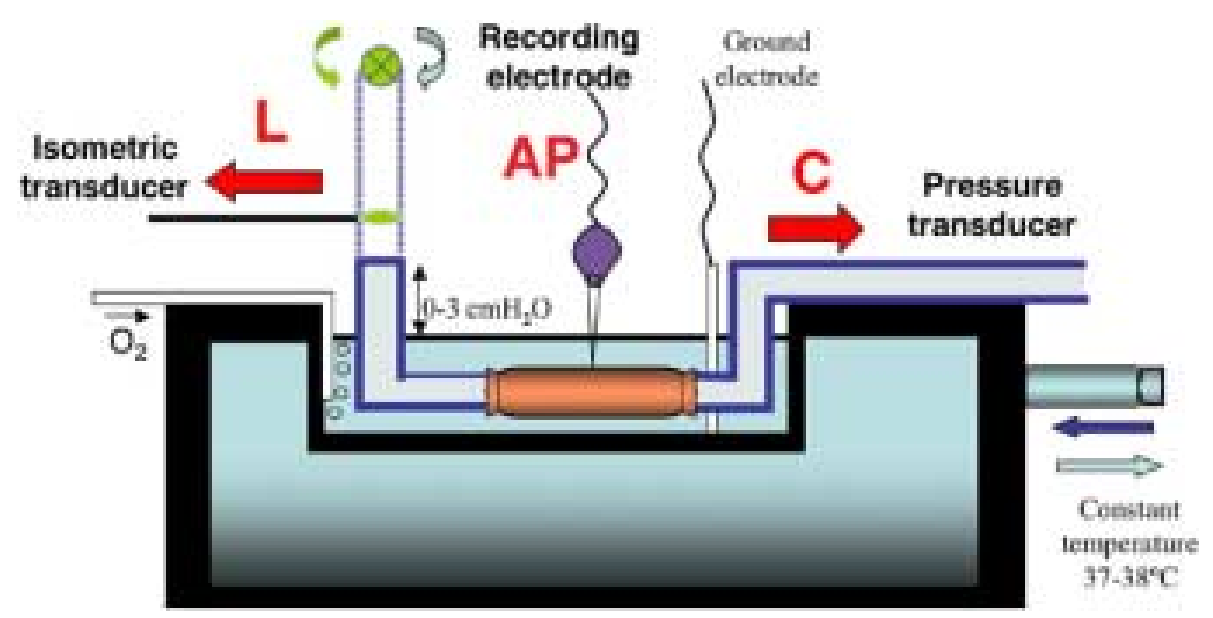

Fig. 3. The apparatus used for the simultaneous recording of spontaneous electrical and mechanical activity in the murine small intestine. AP: action potential. L: longitudinal muscle contractions. C: circular muscle contractions.

\section{+/+ mouse jejunum}

\section{$+/+$ mouse ileum}

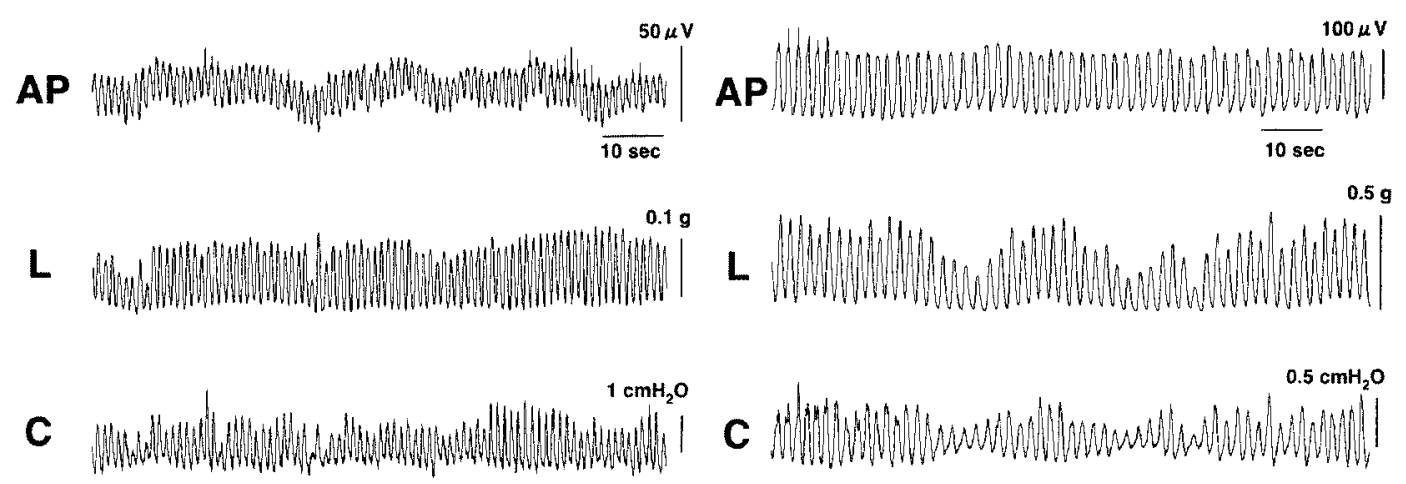

Fig. 4. Simultaneous recordings of spontaneous electrical activity and both longitudinal muscle contractions and circular muscle contractions in +/+ mouse jejunum. AP: action potential. L: longitudinal muscle contractions. C: circular muscle contractions.

inhibited by nitrergic enteric neurons, the frequency of spontaneous motility was not affected by enteric neurons.

As shown in the ileum of $W / W^{v}$ mice in Fig. 6, electrical slow waves could not be found and no regular contractions were found in either of the longitudinal and circular smooth muscle layers. This result indicates that ICC-MY are essential for generating electrical slow waves and a regular rhythm of contraction. Interestingly, however, after treatment with TTX $(0.1 \mu \mathrm{M})$ or LNAME (10 $\mu \mathrm{M})$ (Fig. 6), fairly regular contractions appeared associated with spike potentials, although electrical slow waves were still not evident (Nakagawa et al., 2003; Takaki et al., 2003). This indicates that spontaneous contractions could still occur after blocking the nitrergic 
$+/$ mouse ileum
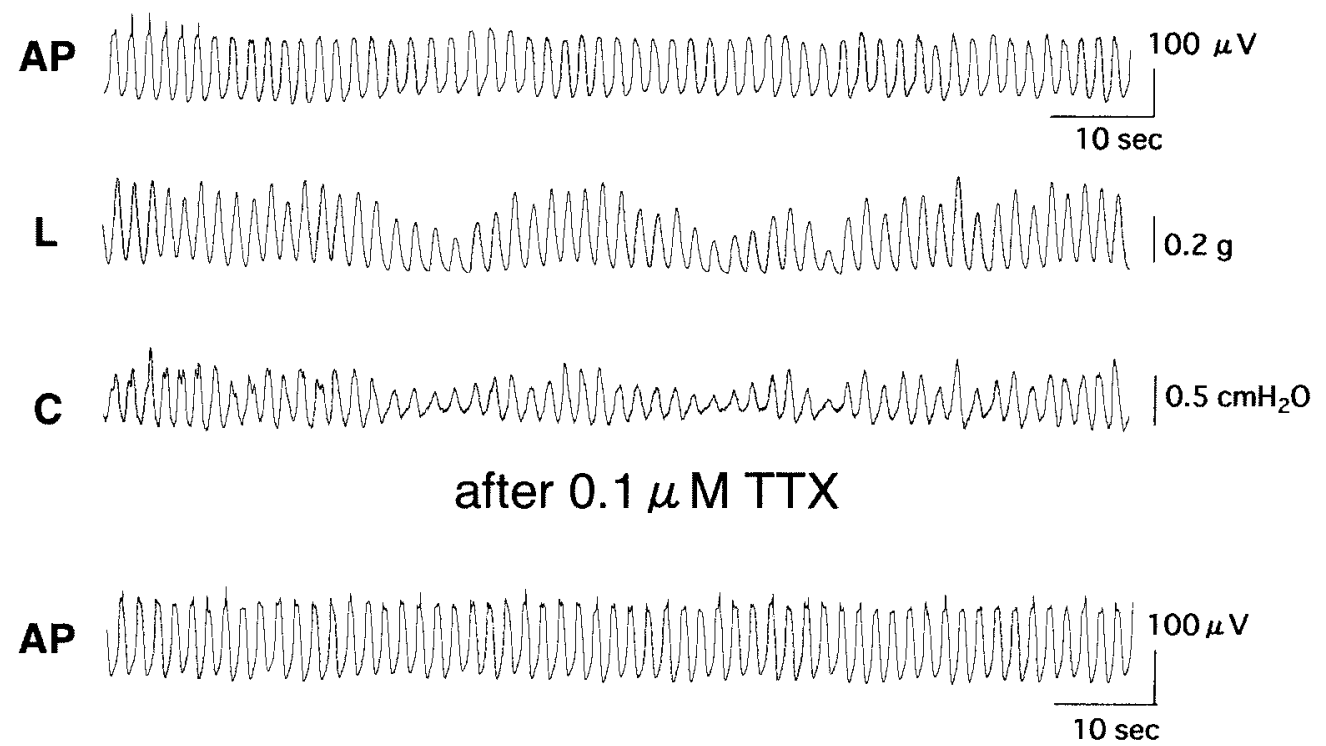

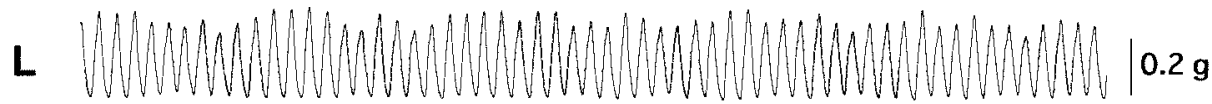

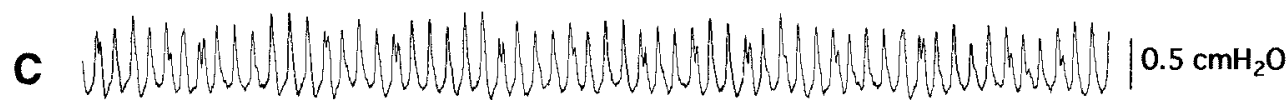

Fig. 5. Effects of tetrodotoxin on simultaneous spontaneous electrical activity and both longitudinal muscle contractions and circular muscle contractions in +/+ mouse ileum. AP: action potential. L: longitudinal muscle contractions. C: circular muscle contractions.

inhibitory neural influences, even if the ICC-MY were absent. These spontaneous contractions may be generated by ICC-IM (according to my nomenclature, i.e. previously ICC-DMP).

The result obtained from $W / W^{v}$ mice suggests the possibility that either ICC-MY and/or ICC-IM (ICC-DMP) are pacemakers in the mouse small intestine. If ICC-MY is deficient, ICCIM (ICC-DMP) could be a primary pacemaker, although there is not much difference between the frequencies of the two ICC networks (compare the frequency in the traces in Fig. 5 with the lower traces after L-NAME in Fig. 6). This is markedly different from the pacemakers in the heart, where the frequency of the pacemaker potentials in SA node cells is higher than that in AV node cells.

\section{Properties of Plateau Potentials in ICC-SM in the Mouse Proximal Colon}

Electrophysiological properties of spontaneously active cells in the mouse proximal colon

Intracellular recordings were made from different types of smooth muscle preparations of the mouse proximal colon. 


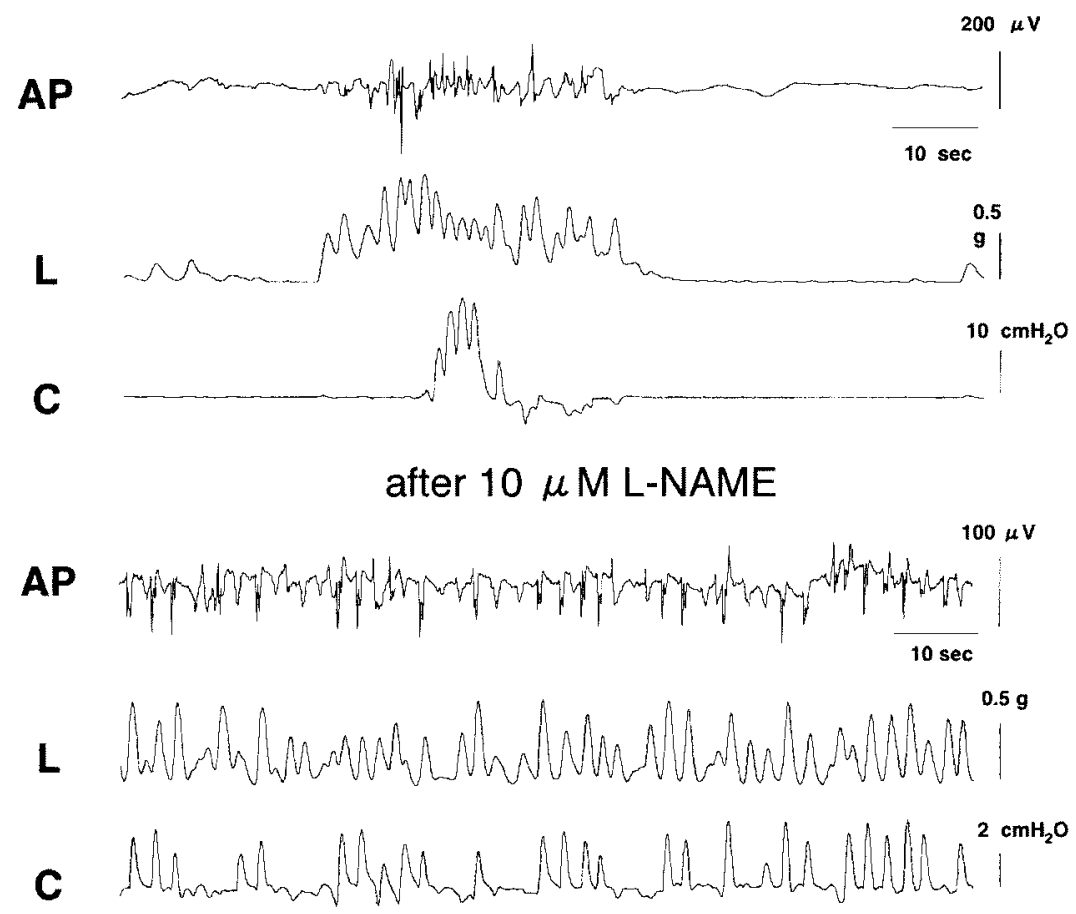

Fig. 6. Effects of an NO synthase inhibitor, nitro-L-arginine methyl ester (L-NAME) on simultaneous spontaneous electrical activity and both longitudinal muscle contractions and circular muscle contractions in the $W / W^{v}$ mouse ileum. Upper traces: before LNAME. Lower traces: after L-NAME $(10 \mu \mathrm{M})$.

\section{Plateau potentials in ICC-SM cells}

In preparations in which the submucosal layer was uppermost, but with the circular and longitudinal smooth muscle layers still attached, square-shaped potential changes consisting of initial fast rising and subsequent plateau components (plateau potentials) were recorded from cells in the submucosa (Fig. 7, A). These plateau potentials were generated at mean frequencies of $14.8 \pm 3.4 \mathrm{~min}^{-1}$, with mean peak amplitudes of $19.6 \pm 6.9 \mathrm{mV}$. The mean rates of rise of the initial potentials were $148 \pm 61 \mathrm{mV} / \mathrm{s}$ and the mean duration of the plateau potentials at the foot were $2.6 \pm 0.3 \mathrm{~s}$. The mean resting membrane potentials of cells generating plateau potentials were $-48.2 \pm 5.9 \mathrm{mV}$. Neither TTX $(1 \mu \mathrm{M})$ nor atropine $(1 \mu \mathrm{M})$ altered the frequency, amplitude or resting membrane potentials of the plateau potentials (Yoneda et al., 2002a).

Bursts of spike potentials in circular smooth muscle cells

In preparations with the circular smooth muscle layer exposed after removal of the submucosal layer, recordings were made from smooth muscle cells which exhibited rhythmic generation of bursts of spike potentials (Fig. 7, B) (Yoneda et al., 2000a). The mean resting membrane potential of these circular smooth muscle cells was $-44.9 \pm 5.5 \mathrm{mV}$. Bursts of spike 


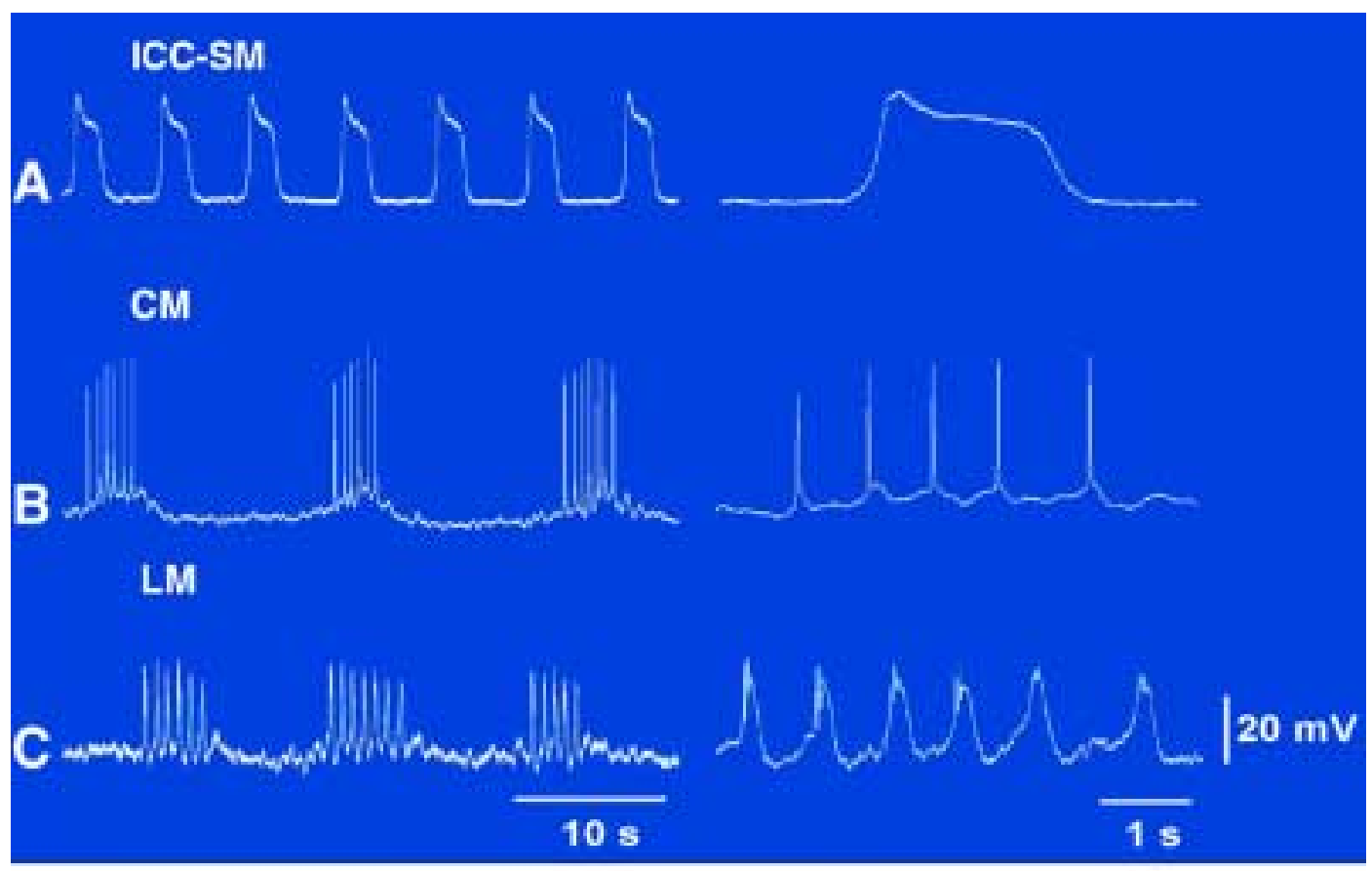

1. Physial 542.3. 897.897, 2002 (with permissian )

Fig. 7. Spontaneous electrical activity recorded from the mouse proximal colon. A: Plateau potentials from an ICC-SM (submucosal ICC). B: Bursts of action potentials in a circular smooth muscle cell. C: Bursts of oscillatory potentials in a longitudinal smooth muscle cell. From Yoneda et al., (2002a).

potentials were generated with a mean frequency of $4.6 \pm 1.1 \mathrm{~min}^{-1}$. Both TTX $(1 \mu \mathrm{M})$ and LNAME $(10 \mu \mathrm{M})$ increased the frequency of the bursts of spike potentials, but atropine $(1 \mu \mathrm{M})$ did not (Yoneda et al., 2002b; Takaki and Yoneda, 2003; Takaki et al., 2003).

\section{Bursts of oscillatory potentials in longitudinal smooth muscle cells}

In preparations with the longitudinal smooth muscle layer exposed after removal of the submucosal layer, recordings were made from smooth muscle cells which exhibited periodic bursts of oscillatory potentials (Yoneda et al., 2002a). The form of these oscillatory potentials differed from both the plateau potentials and spike potentials, as shown in Fig. 7, C. The mean resting membrane potential was $-48.1 \pm 7.2 \mathrm{mV}$. Bursts of oscillatory potentials were generated with a mean frequency of $4.3 \pm 1.3 \mathrm{~min}^{-1}$. Both TTX $(1 \mu \mathrm{M})$ and L-NAME $(10 \mu \mathrm{M})$ increased the frequency of the bursts of oscillatory potentials, but atropine $(1 \mu \mathrm{M}) \operatorname{did}$ not (Yoneda $e t a l$, 2002b; Takaki and Yoneda, 2003; Takaki et al., 2003).

The periodic generation of bursts of either spike potentials or oscillatory potentials in smooth muscle cells was not causally related to the ICC-SM, because the removal of the submucosal layer did not affect their periodic generation and their frequency was quite different from that of the plateau potentials of the ICC-SM. As none of these electrical activities were blocked by either TTX or atropine, it seems unlikely that excitation of cholinergic nerves triggers these electrical activities. It is convincing, however, that enteric nitrergic nerves 


\section{The network of ICC-SM in mouse proximal colon}

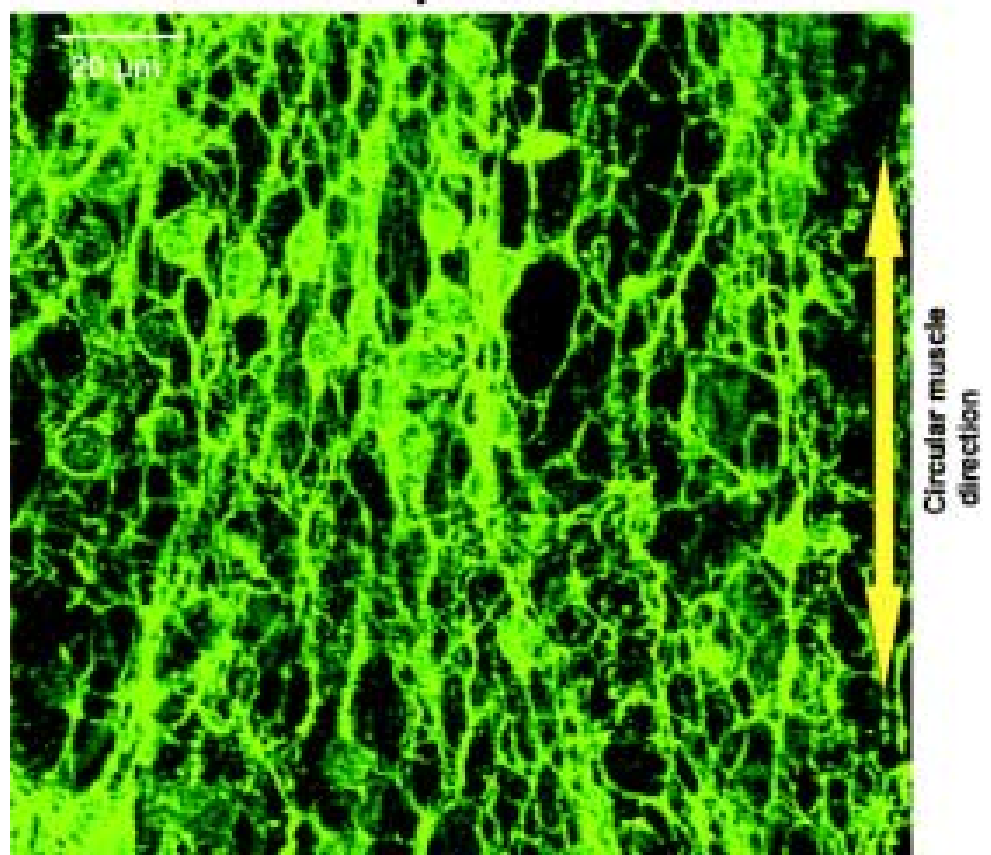

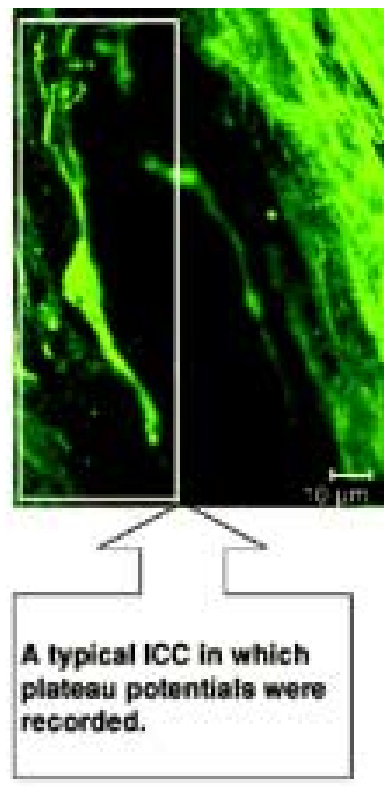

Fig. 8. The morphology of the ICC-SM network in the mouse proximal colon. A typical ICC in which plateau potentials were recorded is also shown.

tonically suppress these electrical activities in smooth muscle cells. This is in contrast to the plateau potentials of ICC-SM cells, in which no enteric nerves modulate the generation of plateau potentials.

\section{Morphology of cells spontaneously generating plateau potentials in the proximal colon}

Neurobiotin was injected into submucosal cells that had demonstrated the generation of plateau potentials. This was done in the presence of $18 \beta$-glycyrrhetinic acid (18 $\beta$-GA, $20 \mu \mathrm{M})$, a known inhibitor of gap junctions in smooth muscle tissues (Yamamoto et al., 1998). The stained cells had oval shaped cell bodies with a maximum diameter of 20-30 $\mu \mathrm{m}$ and a thickness of 5-8 $\mu \mathrm{m}$. Each cell had bipolar processes of $50-150 \mu \mathrm{m}$ in length with the tip of the process often being bifurcated. These cells ran parallel to the circular smooth muscle bundles, suggesting the possibility that an electrical tonic excitation is conducted in the direction of the circular smooth muscle.

Immunohistochemical examination identified a dense network of c-Kit-positive interstitial cells in the submucosal layer at the boundary of the circular smooth muscle layer (Fig. 8), as had been reported by Vanderwinden et al. (2000). The c-Kit-positive cells were distributed in the same layer with the neurobiotin-filled cells and appeared to be similar in shape and size as detailed above. Thus, it would appear that the plateau potentials were recorded from the c-Kit 
A

a

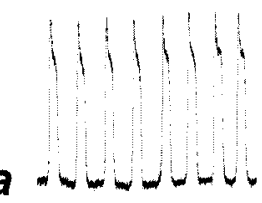

Control b

Nifedipine $0.1 \mu \mathrm{M}$

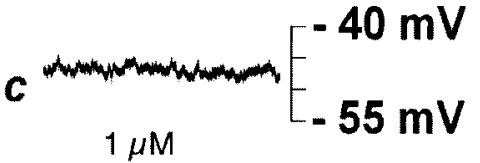

$10 \mathrm{~s}$
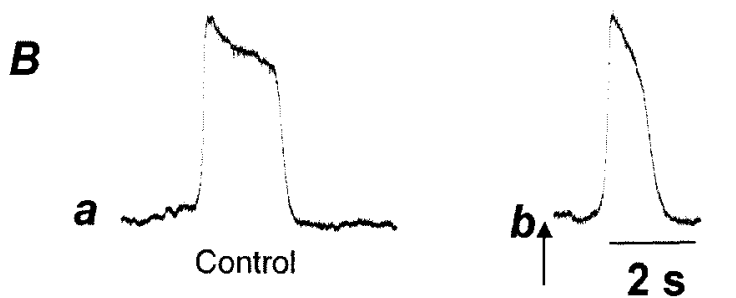

\section{$20 \mathrm{mV}$}

Nifedipine $0.1 \mu \mathrm{M}$

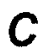

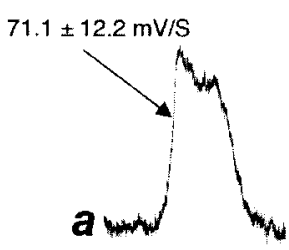

Control

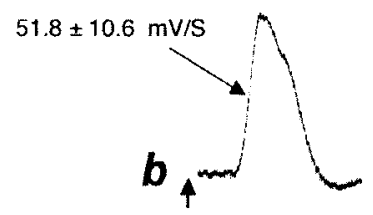

Ni $10 \mu \mathrm{M}$

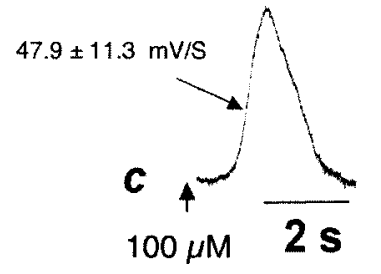

$20 \mathrm{mV}$

Fig. 9. Effects of nifedipine and nickel $(\mathrm{Ni})$ on plateau potentials in an ICC. A: Dose-dependent effects of nifedipine. B: Nifedipine $(0.1 \mu \mathrm{M})$ decreased the duration of the plateau potentials. C: $\mathrm{Ni}(10-100$ $\mu \mathrm{M})$ decreased the rate of rise of initial phase of plateau potentials.

protein-expressing interstitial cells distributed in the submucosal layer (ICC-SM) of the proximal colon. However, the nifedipine sensitivity of the plateau potentials of the ICC-SM of the mouse proximal colon is quite different from that of the other ICC as described below.

\section{Effects of nifedipine and $\mathrm{Ni}^{2+}$ on plateau potentials}

The effects of nifedipine, an inhibitor of voltage-gated L-type $\mathrm{Ca}^{2+}$-channels (Nelson $e$ t al., 1990), were investigated on the spontaneously generated plateau potentials in the ICC-SM (Yoneda et al., 2002a). This was because pacemaker potentials (or currents) in ICC are considered to be nifedipine-resistant (Torihashi et al., 2002). Plateau potentials were still generated with the same frequency in the presence of $0.1 \mu \mathrm{M}$ nifedipine, although the duration of the plateau component was markedly shortened (Fig. 9, Ab). Nifedipine $(0.1 \mu \mathrm{M})$ did not affect the rate of rise of the initial component of plateau potentials $(155 \pm 65 \mathrm{mV} / \mathrm{s}$ in control vs. $148 \pm 69 \mathrm{mV} / \mathrm{s}$ in nifedipine) (Fig. 9, Bb), but nifedipine $(1 \mu \mathrm{M})$ did abolish plateau potentials (Fig. 9, Ac). These observations indicate that the plateau potentials are dependent upon activation of voltage-gated L-type $\mathrm{Ca}^{2+}$-channels. The reason for the nifedipine-sensitivity of plateau potentials in the ICC-SM in the mouse proximal colon remains unknown. 


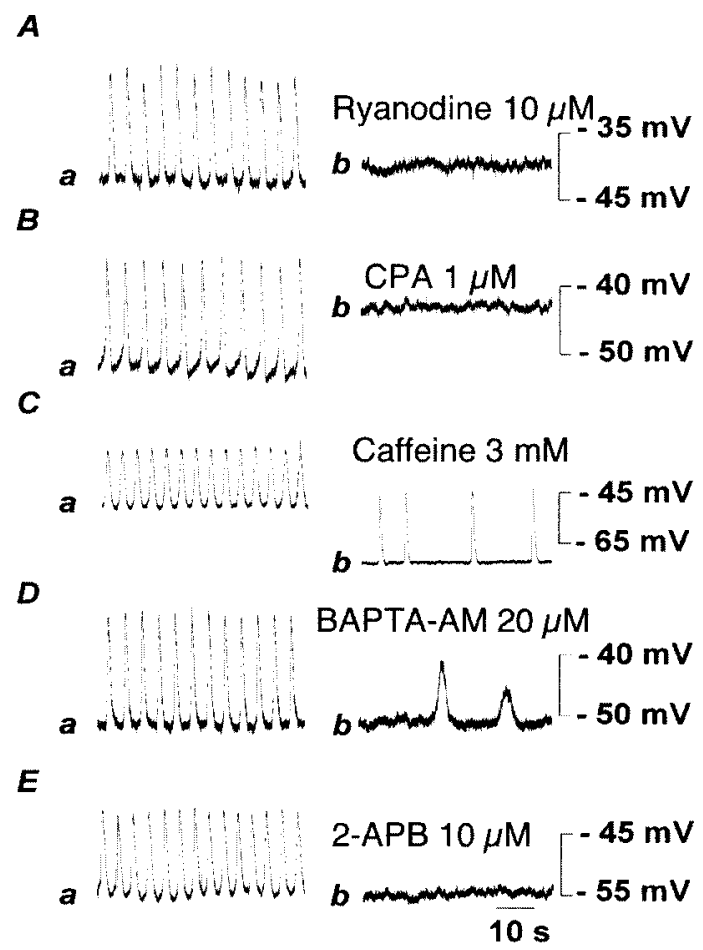

Fig. 10. Modulation of internal $\mathrm{Ca}^{2+}$ store and plateau potentials in ICC. A: Ryanodine (10 $\mu \mathrm{M})$ abolished plateau potentials. B: cyclopiazonic acid (CPA; $1 \mu \mathrm{M})$ abolished plateau potentials with an associated membrane depolarization. C: Caffeine $(3 \mathrm{mM})$ decreased the frequency but increased the amplitude of plateau potentials with an associated membrane hyperpolarization. D: BAPTA-AM $(20 \mu \mathrm{M})$ markedly suppressed plateau potentials. E: 2-aminoethoxy-diphenyl borate (2-APB; $10 \mu \mathrm{M})$ abolished plateau potentials.

Furthermore, $\mathrm{Ni}^{2+}(10-100 \mu \mathrm{M})$, an inhibitor of voltage-gated T-type $\mathrm{Ca}^{2+}$-channels, decreased the rate of rise of plateau potentials but did not abolish the plateau potentials (Fig. 9, C) (Yoneda et al., 2003). These results indicate that two types of voltage-gated channel currents form the plateau potentials: the initial component is $\mathrm{Ni}^{2+}$-sensitive and their plateau component is nifedipine-sensitive.

\section{Effects of internal $\mathrm{Ca}^{2+}$ modulators on plateau potentials}

Ryanodine $(10 \mu \mathrm{M})$ completely abolished plateau potentials (Fig. 10, Ab). CPA (1 $\mu \mathrm{M})$ also completely abolished plateau potentials but with an associated membrane depolarization (Fig. $10, \mathrm{Bb})$. The fact that high $\left[\mathrm{K}^{+}\right]_{\text {o }}$ solution depolarized the membrane by about $25 \mathrm{mV}$, but did not abolish plateau potentials, showed that the inhibition of plateau potentials by CPA is not due to depolarization of the membrane. Caffeine $(3 \mathrm{mM})$ largely decreased the frequency of plateau potentials also with an associated membrane hyperpolarization, although the amplitude increased (Fig. 10, Cb). BAPTA-AM $(20 \mu \mathrm{M})$ also largely decreased the frequency of plateau potentials without any changes in the membrane potential (Fig. 10, Db). 2-APB (10 $\mu \mathrm{M})$ 

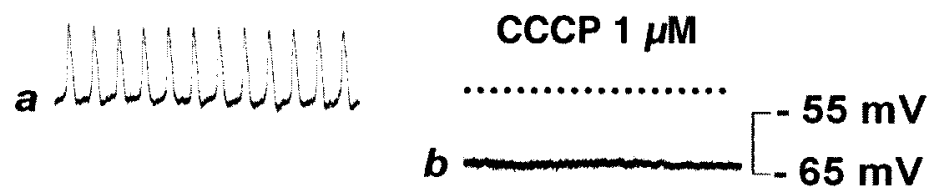

B

\section{Glybenclamide $10 \mu \mathrm{M}$}
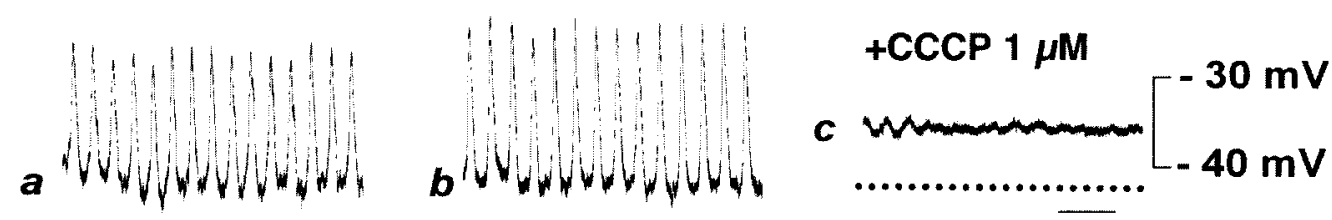

$10 \mathrm{~s}$

Fig. 11. Effects of CCCP, a mitochondria protonophore, on plateau potentials in ICC. A: CCCP (1 $\mu \mathrm{M})$ abolished plateau potentials with an associated membrane hyperpolarization. B: After pretreatment with glybenclamide, a $\mathrm{K}_{\mathrm{ATP}}$ channel blocker, CCCP abolished plateau potentials without causing membrane hyperpolarization. J. Physiol. 542.3, 887-897, 2002 (with permission)

completely abolished plateau potentials Fig. 10, Eb). These results suggest that the $\mathrm{Ca}^{2+}$ release-refilling cycle determines the frequency of plateau potentials as suggested by Liu $e t$ al. (1995). $\mathrm{IP}_{3}$ receptors may also be involved in the process of plateau potential generation as suggested by many researchers (Suzuki, 2000; Suzuki et al., 2000; Hirst and Edwards, 2001; Fukuta et al., 2002). Furthermore, the plateau potentials in the ICC-SM in the proximal colon are modulated by ryanodine receptors. This $\mathrm{Ca}^{2+}$ modulation by ryanodine receptors in the proximal colon is different from that of the $\mathrm{IP}_{3}$ receptors in the mouse and guinea pig stomach (Suzuki, 2000; Suzuki et al., 2000; Hirst and Edwards, 2001; Fukuta et al., 2002).

\section{Role of mitochondrial functions in the plateau potential}

Recently, it was postulated that intracellular $\mathrm{Ca}^{2+}$ handling between an internal $\mathrm{Ca}^{2+}$ store and mitochondria produces the rhythmic activity in cultured myenteric ICC of both the mouse jejunum (Ward et al., 2000) and the guinea-pig stomach (Fukuta et al., 2002). Carbonyl cyanide $m$-chlorophenylhydrazone (CCCP) $(1 \mu \mathrm{M})$, a mitochondrial protonophore (Duchen, 2000), reduced the frequency of plateau potentials, and finally abolished them with an associated membrane hyperpolarization (Fig. 11, Ab). Glybenclamide $(10 \mu \mathrm{M})$, an inhibitor of ATP sensitive $\mathrm{K}^{+}$-channels (Cook, 1988), antagonized CCCP-induced hyperpolarization. In the presence of glybenclamide, CCCP abolished plateau potentials with an associated membrane depolarization (Fig. 11, Bc) (Yoneda et al., 2002a). These results suggest that the inhibition of plateau potentials by CCCP is not causally related to the membrane hyperpolarization. 


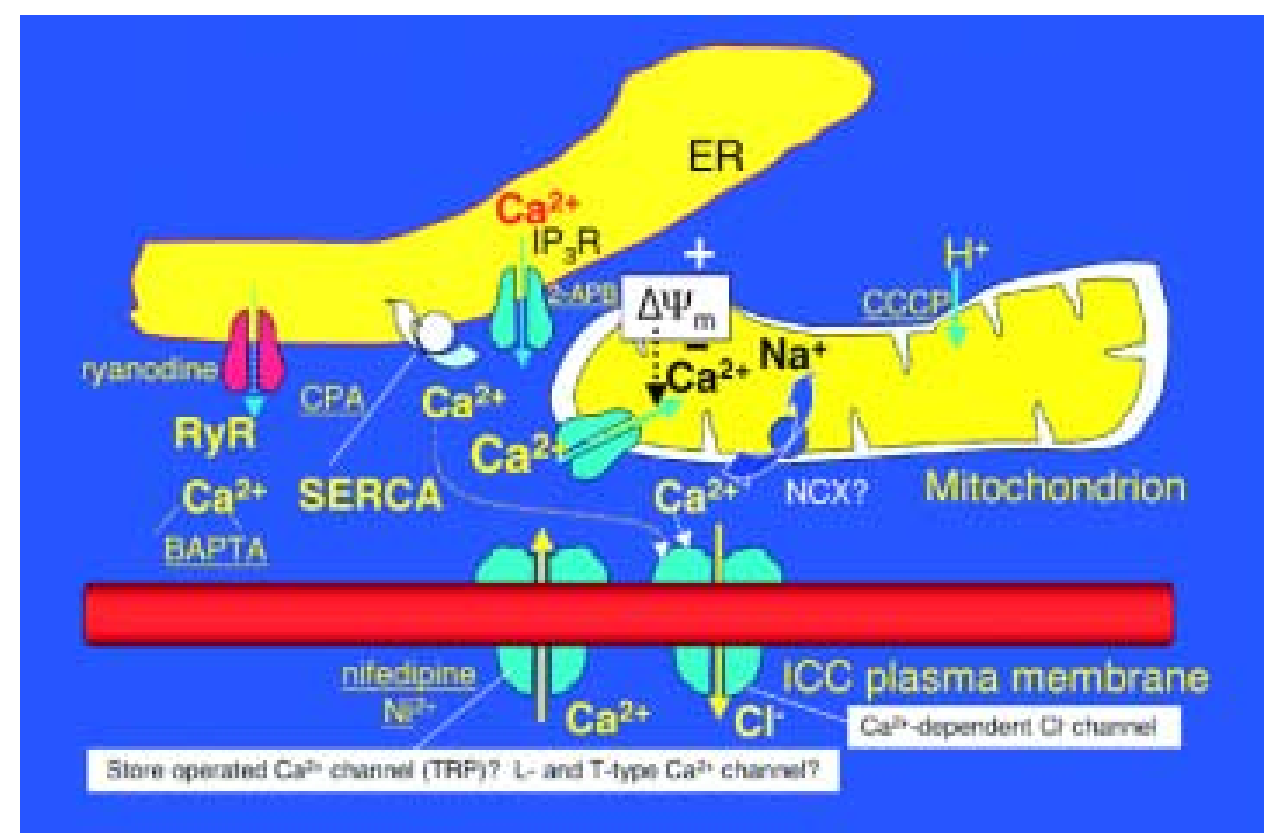

Fig. 12. Model proposed as an explanation for how plasma membrane-endoplasmic reticulummitochondrial $\mathrm{Ca}^{2+}$ handling drives pacemaker currents in ICC. $\mathrm{Ca}^{2+}$ is released from ER via $\mathrm{IP}_{3} \mathrm{R}$ and $\mathrm{RyR}$. Some of the $\mathrm{Ca}^{2+}$ is taken-up by mitochondria driven by the negative membrane potential $\left(\Psi_{\mathrm{m}}\right)$. This $\mathrm{Ca}^{2+}$ uptake by mitochondria activates nonselective cation channels (TRP) in the plasma membrane, resulting in inward pacemaker currents. Voltage-gated $\mathrm{Ca}^{2+}$ channels may also be activated. $\mathrm{Ca}^{2+}$ entry via these channels is partially taken up by ER via SERCA to reset the cycle. NCX removes $\mathrm{Ca}^{2+}$ from mitochondria. $\mathrm{Ca}^{2+}$-dependent $\mathrm{Cl}^{-}$channels are also activated by intracellular $\mathrm{Ca}^{2+}$ to generate pacemaker currents. Which of these components has the primary role is not yet determined, but this is a possible generation mechanism for pacemaker currents. ER: endoplasmic reticulum. IP ${ }_{3} \mathrm{R}$ : inositol 1,4,5-triphosphate receptor. $\mathrm{NCX}: \mathrm{Na}^{+} / \mathrm{Ca}^{2+}$ exchange. RyR: ryanodine receptor. SERCA: ER-Ca ${ }^{2+}$ ATPase. $\Delta \Psi_{\mathrm{m}}$ : negative membrane potential difference.

The proposal that intracellular $\mathrm{Ca}^{2+}$ handling between an internal $\mathrm{Ca}^{2+}$ store and mitochondria produces the rhythmic activity is also supported in the ICC-SM in the mouse proximal colon. The plateau potentials are generated through activation of voltage-gated $\mathrm{Ca}^{2+}$ channels, which are coupled to the release of $\mathrm{Ca}^{2+}$ from the internal stores and the handling of $\mathrm{Ca}^{2+}$ in mitochondria. In addition to voltage-gated $\mathrm{Ca}^{2+}$ channels, several types of plasmalemmal ionic channels that are periodically activated to generate a pacemaker current have been proposed, such as non-selective cation channels including transient receptor potential subfamily ion channels (TRPs), $\mathrm{Ca}^{2+}$-dependent $\mathrm{Cl}^{-}$channels, and/or $\mathrm{Ca}^{2+}$ activated $\mathrm{K}^{+}$channels (Huizinga et al., 1995; Kölbel et al., 1998; Horowitz et al., 1999; Fujita et al., 2001; Huizinga et al., 2002; Torihashi et al., 2002) (Fig. 12).

\section{The possible role of plateau potentials in ICC-SM}

The frequencies of spontaneous electrical activity differs between ICC-SM cells and circular 
and longitudinal smooth muscle cells in the mouse proximal colon (Yoneda et al., 2002a). Therefore, the role of plateau potentials in the ICC-SM remains unknown. A variety of driving mechanisms have been reported for the ICC networks in both different tissues and in different species as follows: 1) ICC-SM and circular smooth muscle cells form networks of gap junctions in the canine proximal colon and thus the ICC-SM drives circular muscle activity (Smith et al., 1987a; Berezin et al., 1988; Sanders and Smith, 1989; Kobayashi et al., 1995). 2) The ICC-MY drives smooth muscle activities in the colon, stomach or small intestine (Sanders, 1996; Huizinga et al., 1997; Sanders et al., 1999). 3) In the rat colon, two independent and distinct pacemakers (ICC-SM and ICC-MY) drive the longitudinal and circular smooth muscle contractions: slow waves derived from the ICC-SM trigger circular smooth muscle contractions and the cyclic oscillatory potentials derived from the ICC-MY trigger both circular and longitudinal smooth muscle contractions (Plujà et al., 2000). 4) Summed signals from ICC-SM and ICC-MY excite circular smooth muscle electrical and mechanical activities in the canine proximal colon (Smith et al., 1987b; Keef et al., 1997).

The mouse proximal colon may differ from other parts of the gastrointestinal tract but may be similar to the rat proximal colon (Plujà et al., 2000). Although peristalsis distally towards the anus could also occur in this pacemaker region, "antiperistalsis" is the first activity to appear in this region in both the rat and guinea pig proximal colon (Hukuhara and Neya, 1968). Thus, it seems likely that plateau potentials in the ICC-SM contribute to the generation of this "antiperistalsis", because the frequency of the plateau potentials is similar to that of the regular contractions at the mesenteric border of the pacemaker area in the guinea-pig proximal colon (Kobayashi et al., 1996).

\section{Two Different Pacemaker Activities Regulate Peristalsis and "Antiperistalsis" in the Mouse Proximal Colon}

The next study was aimed to elucidate how the electrical activities of the ICC-SM and circular and longitudinal smooth muscle cells control spontaneous contractions such as peristalsis and "antiperistalsis" (circular rings of contraction rippling proximally from the pacemaker region) of the mouse proximal colon. The results indicate that the ICC-SM controls the spontaneous small faster circular muscle contractions (possibly corresponding to "antiperistalsis") and another pacemaker (possibly ICC-MY and/or ICC-IM) independently controls the spontaneous big slower circular and longitudinal contractions (possibly corresponding to peristalsis). The pacemaker activity in the ICC-SM during "antiperistalsis" is not regulated by the enteric nervous system, but another possible pacemaker activity during peristalsis is regulated by enteric nitrergic inhibitory nerve.

\section{Properties of mechanical activities in mouse proximal colon}

Periodical rhythmic contractions (big contractions) were recorded in the circular muscle direction of preparations with the submucosa attached. These contractions had a mean frequency of $4 \pm 2$ times/min and a mean amplitude of $0.12 \pm 0.07 \mathrm{~g}$. Between such big contractions, rhythmic smaller contractions (small contractions) were observed. The mean 
frequency of these small contractions was $16 \pm 3$ times/min and was significantly higher than that of the big contractions, but the amplitude of these contractions was one-tenth of the big contractions (Yoneda et al., 2002b; Takaki and Yoneda, 2003; Takaki et al., 2003).

Periodical rhythmic contractions (big contractions) were also recorded in the direction of the longitudinal smooth muscle. The frequency and amplitude of these contractions corresponded to those in the circular muscle direction. Small contractions were not recorded in the longitudinal smooth muscle direction. Small contractions in the circular muscle were not observed after removal of the submucosal layer where the ICC-SM is distributed, but the frequency and amplitude of the big contractions in the circular and longitudinal directions were not affected (Yoneda et al., 2002b; Takaki and Yoneda, 2003; Takaki et al., 2003).

\section{Simultaneous recordings of mechanical and electrical activities in the proximal colon}

The faster small circular contractions were generated synchronously with the plateau potentials in the ICC-SM. The big contractions in the direction of the circular or longitudinal smooth muscle directions were generated asynchronously with the plateau potentials, but synchronously with bursts of action potentials in the circular smooth muscle cells or with bursts of oscillatory potentials in longitudinal smooth muscle cells. The frequency of the big contractions was completely different from that of the plateau potentials in the ICC-SM (Yoneda et al., 2002b, Takaki and Yoneda, 2003; Takaki et al., 2003). The frequency of the big contractions and the frequency of both bursts of action potentials and oscillatory potentials were not changed after removal of the submucosal layer, indicating that the big contractions are not causally related to the ICC-SM. These results suggest that the electrical and mechanical activities of the smooth muscle layers are derived from two pacemaker activities (ICC-SM and another possible pacemaker such as ICC-MY and/or ICC-IM) and that these two or three pacemakers regulate the mechanical activity of the smooth muscle coats.

\section{Role of cholinergic and nitrergic nerves on the electrical and mechanical activities in circular and longitudinal smooth muscle cells}

The electrical activities recorded from the ICC-SM were not affected by TTX or atropine, suggesting that enteric nerves do not control these activities as mentioned above (Yoneda $\mathrm{et} \mathrm{al \text {., }}$ 2002a). To reveal possible neural control mechanisms for the slower big contractions possibly generated by another pacemaker activity, the effects of TTX, atropine and a nitric oxide (NO) synthase inhibitor, L-NAME were tested on the big contractions in circular and longitudinal muscle directions and on corresponding bursts of action potentials in circular muscle cells and on bursts of oscillatory potentials in longitudinal muscle cells.

While TTX $(0.1 \mu \mathrm{M})$ increased the frequency of the big contractions from 3 to $\sim 4-5$ times/ min and also increased the frequency of both bursts of action potentials and oscillatory potentials without changes in the resting membrane potential, atropine $(1 \mu \mathrm{M})$ did not. LNAME $(10 \mu \mathrm{M})$ increased the frequency of the big contractions from 3-4 to 5-6 times/min and also increased the frequency of both bursts of action potentials and oscillatory potentials without changes in the resting membrane potential. These inhibitory effects of nitrergic nerves on another possible pacemaker activity are consistent with those in the canine proximal colon 
(Keef et al., 1997) and in the ileum of the $W / W^{v}$ mutant mouse (Nakagawa et al., 2003; Takaki et $a l ., 2003)$, where the spontaneous electrical and mechanical activities might be tonically suppressed by basal release of NO.

No inhibitory effects of intracellular $\mathrm{Ca}^{2+}$ modulators on electrical activities in circular and longitudinal smooth muscle cells

CPA $(10 \mu \mathrm{M})$ depolarized the membrane potentials in circular and longitudinal smooth muscle cells and consequently increased the frequency or abolished both the bursts of action potentials in circular muscle cells and the oscillatory potentials in longitudinal muscle cells. BAPTA $(20 \mu \mathrm{M})$ did not change the frequency of both bursts of action potentials and oscillatory potentials, and resting membrane potentials. 2-APB $(10 \mu \mathrm{M})$ depolarized the membrane potentials in circular and longitudinal smooth muscle cells and increased the frequency of both bursts of action potentials and oscillatory potentials, and finally continuously generated action potentials and oscillatory potentials (Yoneda et al., 2002b). The results of 2-APB, BAPTA and $\mathrm{CPA}$ indicated that the release of $\mathrm{Ca}^{2+}$ from internal stores through $\mathrm{IP}_{3}$ receptors does not play a major role in the generation of electrical activity in circular and longitudinal smooth muscle cells.

\section{Role of two different pacemaker activities in the mouse proximal colon}

In conclusion, in the mouse proximal colon, the ICC-SM regulates only the spontaneous faster rhythmic small contractions in the circular muscle direction and another pacemaker (possibly ICC-MY and/or ICC-IM) independently regulates the spontaneous slower periodical rhythmic big contractions in the circular and longitudinal muscle directions. No enteric nerves regulate pacemaker activity in the ICC-SM, whereas nitric oxide (NO) inhibitory enteric nerves control another pacemaker activity. Intracellular $\mathrm{Ca}^{2+}$ release from the internal stores through $\mathrm{IP}_{3}$ receptors and ryanodine receptors play a major role in the generation of pacemaker activity in the ICC-SM, but not for the generation of another pacemaker activity recorded in the circular and longitudinal smooth muscle cells. These results are in contrast to the dog proximal colon, where the activity of smooth muscle cells is the result of the summation of inputs from two discrete populations of pacemakers, the ICC-SM and the ICC-MY (Smith et al., 1987b; BarajasLopez and Huizinga, 1989; Keef et al., 1997).

\section{Peristalsis and "antiperistalsis" in the mouse proximal colon}

In rats and guinea pigs, "antiperistalsis" is initiated in a special region of the proximal colon, termed the "pacemaker area” (Hukuhara and Neya, 1968). This area has been reported to contain bipolar or multipolar cells in the submucosa which express c-Kit proteins, in addition to the ICC-MY (Nahar et al., 1998). "Antiperistalses” are composed of circular muscle contractions which ripple proximally from the pacemaker area and thus contribute to the retention and mixing of the contents as well as preventing a too rapid transportation of the intraluminal contents by peculiar constriction rings (tonic and local circular muscle contractions) in the proximal colon. Consequently, the intraluminal contents would stay longer in the proximal colon and allow more effective water absorption and the formation of solid feces. 
As described above, the two different mechanical activity patterns of the mouse proximal colon are similar to those in the rat colon (Plujà et al., 2000). Rhythmic contractions with a frequency of 10-12 times/min are generated in the pacemaker region of the guinea-pig proximal colon, with a different frequency to other regions of the colon (Kobayashi et al., 1996). The frequency of these rhythmic contractions is comparable to that of the plateau potentials in the ICC-SM and to the small faster contractions in the circular muscle direction in the mouse proximal colon. Small contractions in the circular muscle direction driven by the ICC-SM may correspond to the "antiperistalsis" observed in situ by Hukuhara and Neya (1968). Moreover, peculiar constriction rings moving distally are also observed in the proximal colon of rats and guinea pigs (Hukuhara and Neya, 1968). Big contractions driven by another pacemaker may be related to these peculiar distally moving constriction rings observed in situ. When these small faster and slower big contractions are well coordinated, solid feces could be made from semiliquid intraluminal contents in the mouse proximal colon and propelled to the distal colon.

\section{Gut-like Clusters Differentiated from Embryonic Stem Cells as a Good Model for Exploring Generation Mechanisms of Gut Spontaneous Motility}

Hukuhara et al., $(1961,1962)$ have shown that enteric ganglion cells are essential for the intestinal intrinsic reflex but not for spontaneous motility of the intestine. Enteric nerves, however, could modulate some types of spontaneous motility such as slower big contractions in the mouse proximal colon (Yoneda et al., 2002b; Takaki and Yoneda, 2003). Moreover, in the $W / W^{v}$ mutant mouse ileum where the ICC-MY is deficient, enteric nerves could modulate spontaneous motility (Nakagawa et al., 2003; Takaki et al., 2003). Therefore, the contribution of the enteric neural plexus and the ICC networks to spontaneous rhythmic activity in the gut is still not certain.

Recently, embryonic stem (ES) cells gave rise to a functional organ-like unit, the "gut" (ESgut), which demonstrated peristalsis-like motility and was morphologically well-organized with enteric derivatives of all three embryonic germ layers: epithelial cells (endoderm), smooth muscle cells and interstitial cells of Cajal (ICC) (mesoderm), and enteric neurons (ectoderm) (Yamada et al., 2002). On approximately day-21 of outgrowth culture, the ES-gut showed distinct and highly coordinated contraction patterns with regular rhythms. This mechanical activity was composed of periodic contraction and relaxation. It was very similar to gastrointestinal (GI) motility, i.e. peristalsis and local back-and-forth and segmenting movements. The ICC and/or enteric neurons could coordinate GI motility.

Many types of ES clusters can form, because ES cells have a pluripotent ability to differentiate into a wide range of cell types. Therefore, to obtain a good model for exploring generation mechanisms of gut spontaneous motility, specific differentiation needs to be induced by adding exogenous factors. Before doing this, physiological and morphological properties of spontaneously differentiated ES clusters need to be investigated.

In order to gain insight into the mechanisms involved in the generation of spontaneous motility as in the mammalian GI (Suzuki et al., 2000; Ward et al., 2000; Torihashi et al., 2002), physiological and morphological properties of the ES-gut on approximately day-21 of embryoid 

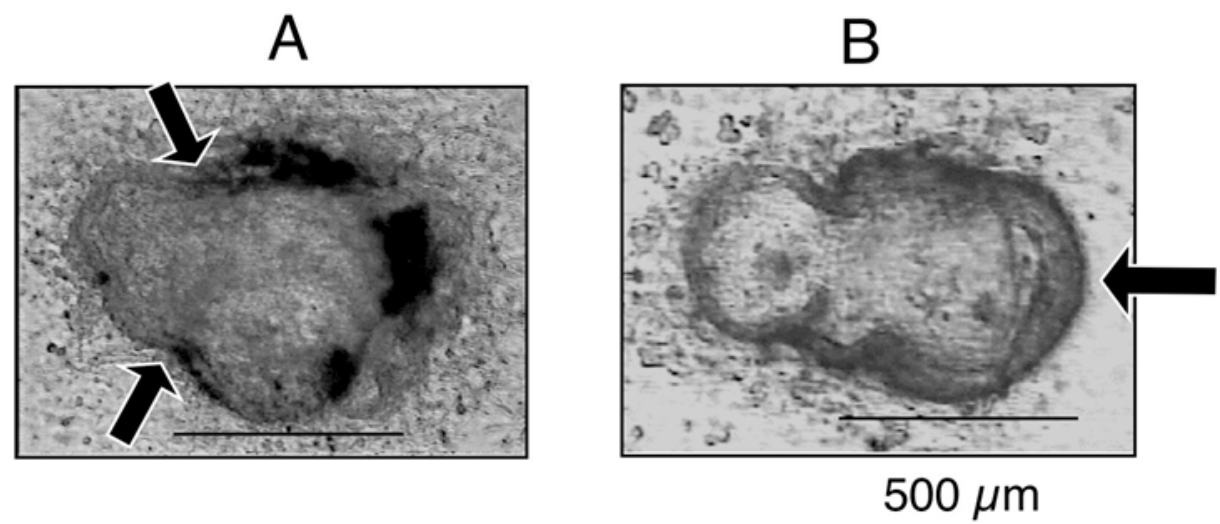

Fig. 13. Two gut-like organs differentiated from embryonic stem cells. Arrows showing the actively moving sites.

body (EB) outgrowth culture were investigated by analyzing spontaneous motility, electrical activity and intracellular $\mathrm{Ca}^{2+}$ movements as well as by immunohistochemistry and electron microscopy.

\section{Spontaneous motilities in ES-gut}

A variety of motility patterns are observed in ES clusters. A tubular (but hemispherical) cluster showed distinct patterns of highly coordinated peristalsis-like contractions (data not shown) and a dome-like cluster showed local back-and-forth contractions (Fig. 13B). Each mechanical activity was composed of a periodic contraction (Fig. 13A) and relaxation.

The mean frequency of spontaneous motility in ES clusters was $\sim 14 \mathrm{cpm}$ on day-21 of embryoid body (EB) outgrowth culture, but this was temperature-dependent. A voltage-gated Ltype $\mathrm{Ca}^{2+}$ channel blocker, nifedipine $(0.1-10 \mu \mathrm{M})$ dose-dependently decreased the frequency of the motility. An agent inhibiting neural activity via $\mathrm{Na}^{+}$channel blockade (TTX; $0.1-1 \mu \mathrm{M}$ ) did not affect the frequency of spontaneous periodic contractions. Ryanodine $(0.1-10 \mu \mathrm{M})$ dosedependently decreased the frequency, whereas 2-APB (1-10 $\mu \mathrm{M})$ only slightly decreased the frequency (Ishikawa et al., 2003).

\section{Electrophysiological studies}

Plateau potentials, which are possibly pacemaker potentials in ICC, were recorded from a twin hemispherical cluster as shown in Fig. 14 (Ishikawa et al., 2003). The mean amplitude of these potentials was approximately $43 \mathrm{mV}$. The mean rate of rise of these potentials was approximately $30 \mathrm{mV} / \mathrm{s}$. After treatment with an L-type $\mathrm{Ca}^{2+}$-channel blocker, nifedipine $(5 \mu \mathrm{M})$, the plateau potentials unchanged. Electrical slow waves at a frequency range of 1-18 cpm (mean: $\sim 8 \mathrm{cpm}$ ) were frequently recorded at $35^{\circ} \mathrm{C}$ from what were possibly smooth muscle cells.

\section{Calcium oscillation in ES clusters}

Synchronous $\left[\mathrm{Ca}^{2+}\right]_{i}$ oscillations propagate widely over the ES clusters. The 


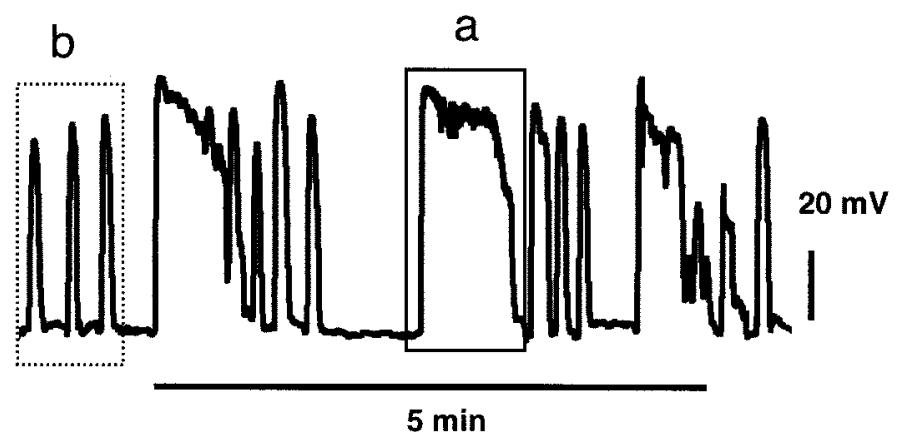

Fig. 14. Plateau potentials possibly within an ICC of a gut-like organ differentiated from embryonic stem cells. a: a single long-duration plateau potential. b: several shortduration plateau potentials.

pharmacological properties of these $\left[\mathrm{Ca}^{2+}\right]_{\mathrm{i}}$ oscillations were investigated. In the presence of nifedipine $(10 \mu \mathrm{M})$, the $\left[\mathrm{Ca}^{2+}\right]_{\mathrm{i}}$ oscillations over the cluster appeared to decrease but were not abolished, whereas spontaneous contractions were abolished. When additional $40 \mu \mathrm{M} \mathrm{Ni}^{2+}$ was applied, the remaining $\left[\mathrm{Ca}^{2+}\right]_{\mathrm{i}}$ oscillations frequently almost disappeared (Ishikawa et al., 2003). Application of $10 \mu \mathrm{M}$ ryanodine almost always significantly decreased the frequency of $\left[\mathrm{Ca}^{2+}\right]_{\mathrm{i}}$ oscillation.

\section{Immunohistochemistry}

Immunoreactivity for c-Kit, a useful marker for ICC (Der-Silaphet et al., 1998; Thomsen et al., 1998; Torihashi et al., 1997), was detected in clusters on day-21 of EB culture that had spontaneous contractions at a regular rhythm and generated electrical slow waves (Yamada $e t$ $a l ., 2002$; Ishikawa $e t$ al., 2003). The hemispherical dome-like cyst showed a large number of $c$ Kit immunopositive ( $c$-Kit+) cells on the wall of the dome-like structure surrounding the lumen. The $c$-Kit+ cells were mostly multipolar, and formed a distinct and dense network. This network structure of c-Kit+ cells was similar to that of ICC at the level of the myenteric plexus (ICC-MY) in the pylorus, small intestine, and colon of a murine embryo or neonate, as described by Torihashi et al. (1997). The $c$-Kit+ cells did not form a single layer, but were scattered throughout the muscle layer.

\section{Ultrastructure of ICC within the musculature of the contracting ES clusters}

As described above, the wall of the cluster was constituted of three layers, i.e. epithelium, submucosa and musculature (Yamada et al., 2002). The musculature consisted of smooth muscle cells. Although the musculature was not well organized, several smooth muscle cells ran in the same direction and the musculature was divided into two or more layers (Ishikawa $e t$ $a l ., 2003)$. Interstitial cells showing some ultrastructural features of ICC were confirmed within the musculature, as previously reported by Yamada et al. (2002). The ICC frequently formed close contacts with neighboring smooth muscle cells. Gap junctions were also observed between a variety of components (Yamada et al., 2002; Ishikawa et al., 2003; Takaki et al., 2003). 
ES gut as a good model for exploring generation mechanisms of spontaneous rhythm

Although the ES-gut lacked some components, such as lymphatic vessels and vascular formation, we have shown that the ES-gut has the essential transmural morphological organization found in a normal intestine (Yamada et al., 2002). Thus, the ES cell-derived gut could be a good model to clarify the mechanism by which GI motility is regulated.

In this study, we have confirmed that an organized gut is generated in vitro from developing EBs in the absence of exogenously added growth factors. This suggests the possibility that in the presence of exogenously added growth factors we could differentiate a particular ES-gut with uniform physiological and morphological properties of its cellular components such as being ICC-deficient, or having well differentiated enteric neurons, or well differentiated endocrine glands, or with well differentiated $\mathrm{IP}_{3}$ receptors and/or ryanodine receptors.

\section{Intracellular $\mathrm{Ca}^{2+}$ circuit}

It has been proposed that the periodic activation of plasmalemmal ion channels to generate pacemaker currents triggers the intracellular release of $\mathrm{Ca}^{2+}$ from endoplasmic reticulum (ER). This $\mathrm{Ca}^{2+}$ release is mediated through inositol triphosphate $\left(\mathrm{IP}_{3}\right)$ type 1 receptors in the ER with subsequent entry of $\mathrm{Ca}^{2+}$ into mitochondria (Suzuki et al., 2000; Ward et al., 2000). These processes are very similar to those observed in cultured cell clusters isolated from mouse intestine (Nakayama and Torihashi, 2002; Torihashi et al., 2002). Ryanodine, however, largely decreased the frequency of both $\mathrm{Ca}^{2+}$ oscillations and spontaneous motility in the ES clusters on 21-day outgrowth, suggesting the possibility that ryanodine receptors are differentiated and contribute to intracellular $\mathrm{Ca}^{2+}$ movements. Differentiation of either ryanodine or $\mathrm{IP}_{3}$ receptors or both types of receptors is expected in the ES-gut.

\section{Plasmalemmal ionic channels}

In contrast to the evidence for an intracellular $\mathrm{Ca}^{2+}$ circuit, plasmalemmal ionic channels that are periodically activated to generate pacemaker currents have not been demonstrated. Several candidates for the role of plasmalemmal ionic channels such as non-selective cation channels which include a transient receptor potential subfamily ion channel (TRPs), $\mathrm{Ca}^{2+}$-dependent $\mathrm{Cl}^{-}$ channels, and/or $\mathrm{Ca}^{2+}$ activated $\mathrm{K}^{+}$channels have been reported (Kölbel et al., 1998; Horowitz et al., 1999; Fujita et al., 2001; Huizinga et al., 2002; Torihashi et al., 2002). Furthermore, it has been found that L-type and T-type $\mathrm{Ca}^{2+}$ channels contribute to the generation of the pacemaker potentials in the ICC-SM of the mouse proximal colon (Yoneda et al., 2002a; 2003). T-type Ca ${ }^{2+}$ channels may contribute to the generation of the pacemaker potential in ICCs of the ES cluster.

\section{Conduction of pacemaker currents from ICC}

Effective electrical coupling between ICC and smooth muscle cells in the ES cluster is likely to occur, because gap junctions were observed between a variety of cellular components (Yamada et al., 2002; Ishikawa et al., 2003; Takaki et al., 2003). Indeed, the frequency of electrical slow waves and of the widely propogated $\mathrm{Ca}^{2+}$ oscillations corresponds to that of the spontaneous motility of the ES clusters, suggesting that there is an efficient conduction of pacemaker currents between the ICC and smooth muscle cells in the ES clusters. However, the 
Table 1 Summary of autonomic rhythmicity in the gut

\begin{tabular}{|c|c|c|c|c|}
\hline \multirow[t]{2}{*}{ organ } & \multicolumn{2}{|c|}{ Rhythm (mean cpm) } & \multirow[t]{2}{*}{ Neural regulation } & \multirow{2}{*}{$\begin{array}{c}\text { Intracellular } \mathrm{Ca}^{2+} \\
\text { modulation }\end{array}$} \\
\hline & Electrical & Mechanical & & \\
\hline \multicolumn{5}{|l|}{$+/+$ mouse } \\
\hline Jejunum & 47 & 47 & No regulation & \multirow{5}{*}{ Not tested } \\
\hline Ileum & 40 & 40 & No regulation & \\
\hline$W / W^{v}$ mouse & & & & \\
\hline Jejunum & \multirow{2}{*}{\multicolumn{2}{|c|}{$\begin{array}{l}\text { Less rhythmicity } \\
\text { No rhythmicity }\end{array}$}} & Slight inhibition & \\
\hline Ileum & & & Nitregic inhibition & \\
\hline \multicolumn{5}{|l|}{ BALB/C mouse } \\
\hline \multicolumn{5}{|l|}{ Proximal colon } \\
\hline ICC-SM & 15 & $16^{\mathrm{a}}$ & No regulation & Important \\
\hline Circular muscle cells & 5 & 5 & Nitrergic inhibition & Not important \\
\hline Longitudinal muscle cells & 4 & 5 & Nitrergic inhibition & Not important \\
\hline ES-gut & 8 & 14 & No regulation $(?)^{\mathrm{b}}$ & Important \\
\hline
\end{tabular}

a, Antiperistalsis, ripple circular muscle contractions transmitted from anal to oral side. b, Enteric neurons are not well-differentiated.
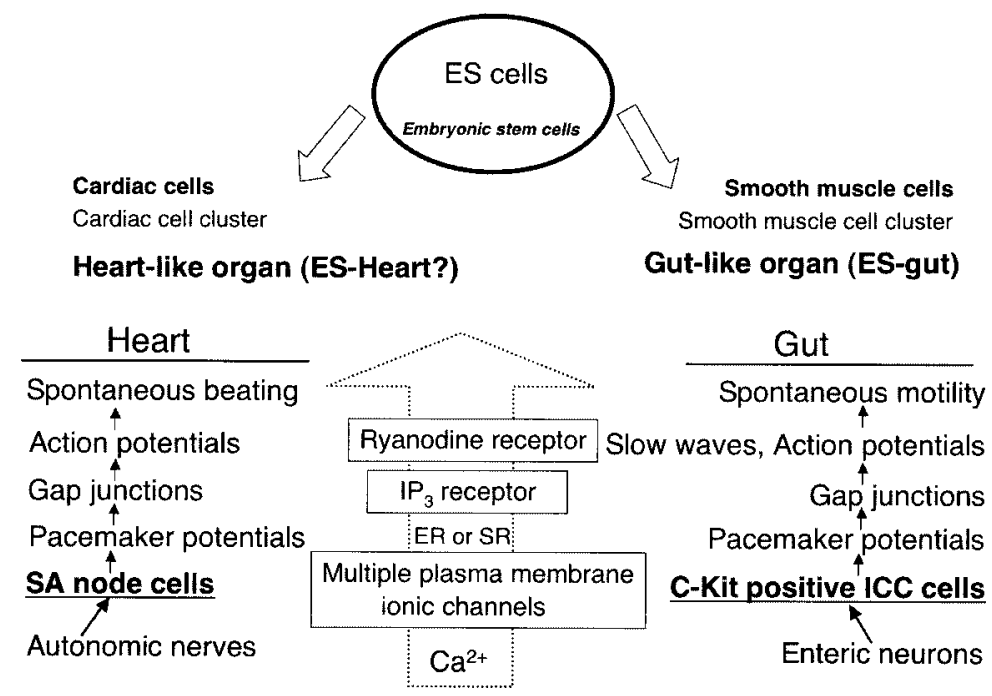

Fig. 15. Summary of the generation of spontaneous motility in the gut compared with that of spontaneous beating in the heart. The similarity between the gut and the heart including that of $\mathrm{Ca}^{2+}$ handling mechanisms is emphasized.

frequency of the electrical slow waves, the $\mathrm{Ca}^{2+}$ oscillations and of the spontaneous motility exhibited considerable variation. Well differentiated gap junctions between the ICC, smooth muscle cells and enteric neurons would be expected in the ES gut by adding exogenous growth factors or by gene transfer. Table 1 shows summary of autonomic rhythmicity, neural regulation and intracellular $\mathrm{Ca}^{2+}$ modulation on the rhythmicity of the gut in this review.

In conclusion, neural regulation of rhythmicity occurs in the gut as it does in the heart, and intracellular $\mathrm{Ca}^{2+}$ handling mechanisms plays a key role in the gut pacemaker responsible for spontaneous rhythmicity as it does for the cardiac pacemaker responsible for spontaneous 
beating, as shown in Fig. 15. Although detailed $\mathrm{Ca}^{2+}$ handling mechanisms for the generation of rhythmicity are different, the role-players are very similar for both gut pacemaker and cardiac pacemaker cells.

\section{Acknowledgments}

The author thanks Drs. T. Nakagawa, S. Yoneda and T. Ishikawa for the contribution to obtain experimental data in this review. This work was supported by Grants-in-aid for Scientific Research $(14370189,14657311)$ from the Ministry of Education, Science, Sports and Culture of Japan.

\section{References}

Barajas-Lopez, C. and Huizinga, J.D. (1989). Different mechanisms of contraction generation in circular muscle of canine colon. Am. J. Physiol. 256: G570-G580.

Berezin, I., Huizinga, J.D. and Daniel, E.E. (1988). Interstitial cells of Cajal in the canine colon: special communication network at the inner border of the circular muscle. J. Comp. Neurol. 273: 42-51.

Cook, N.S. (1988). The pharmacology of potassium channels and their therapeutic potential. Trend. Pharmacol. Sci. 9: 21-27.

Costa, M., Hennig, G.W. and Brookes, S.J. (1998). Intestinal peristalsis: a mammalian motor pattern controlled by enteric neural circuits. Ann. N.Y. Acad. Sci. 860: 464-466.

Cui. Z.J. and Kanno, T. (1997). Photodynamic triggering of calcium oscillation in the isolated rat pancreatic acini. J. Physiol. (Lond.) 290: 11-20.

Der-Silaphet, T., Malysz, J., Hagel, S., Larry Arsenault, A. and Huizinga, J.D. (1998). Interstitial cells of Cajal direct normal propulsive contractile activity in the mouse small intestine. Gastroenterol. 114: 724-736.

Dickens, E.J., Hirst, G.D.S. and Tomita, T. (1999). Identification of rhythmically active cells in guinea-pig stomach. J. Physiol. (Lond.) 514: 515-531.

Duchen, M.R. (1999). Contribution of mitochondria to animal physiology: from homeostatic sensor to calcium signaling and cell death. J. Physiol. (Lond.) 516: 1-17.

Fujita, A., Takeuchi, T., Saitoh, N., Hanai, J. and Hata, F. (2001). Expression of $\mathrm{Ca}^{2+}$-activated $\mathrm{K}^{+}$ channels, SK3, in the interstitial cells of Cajal in the gastrointestinal tract. Am. J. Physiol. 281: C1727-C1733.

Fukuta, H., Kito, Y. and Suzuki, H. (2002). Spontaneous electrical activity and associated changes in calcium concentration in guinea-pig gastric smooth muscle. J. Physiol. (Lond.) 540: 249-260.

Hirst. G.D.S. and Edwards, F.R. (2001). Generation of slow waves in the antral region of guinea-pig stomach - a stochastic process. J. Physiol. (Lond.) 535: 165-180.

Hooper, M., Hardy, K., Handyside, A., Hunter, S. and Monk, M. (1987). HPRT-deficient (Lesch-Nyhan) mouse embryos derived from germline colonization by cultured cells. Nature 326: 292-295.

Horowitz, B., Ward, S.M. and Sanders, K.M. (1999). Cellular and molecular basis for electrical rhythmicity in gastrointestinal muscles. Annu. Rev. Physiol. 61: 19-43.

Huizinga, J.D., Thuneberg. L., Klüppel. M., Malysz, J., Mikkelesen, H. and Bernstein, A. (1995). W/kit gene required for interstitial cells of Cajal and for intestinal pacemaker activity. Nature 373 : 347-349.

Huizinga, J.D., Thuneberg, L., Vanderwinden, J-M. and Rumessen, J. (1997). Interstitial cells of Cajal as targets for pharmacological intervention in gastrointestinal motor disorders. Trend. Pharmacol. Sci. 18: 393-402. 
Huizinga, J.D., Zhu, Y., Ye, J. and Molleman, A. (2002). High conductance chloride channels generate pacemaker currents in interstitial cells of Cajal. Gastroenterol. 123: 1627-1636.

Hukuhara, T. and Neya, T. (1968). The movements of the colon of rats and guinea pigs. Jpn. J. Physiol. 18: $551-562$

Hukuhara, T., Kotani, S. and Sato, G. (1962). Comparative studies on the motility of the normal, denervated and aganlionic THIRY-loops. Jpn. J. Physiol. 12: 348-356.

Hukuhara, T., Sumi T. and Kotani, S. (1961). The role of the ganglionic cells in the small intestine taken in he intestinal intrinsic reflex. Jpn. J. Physiol. 11: 281-288.

Ishikawa, T., Nakayama, S., Horiguchi, K., Misawa, H., Nakagawa, T., Nakao, A., Komuro, T. and Takaki, M. (2003). Interrelations between spontaneous motility and interstitial cells of Cajal in gut-like clusters from embryonic stem cells. Enteric Nervous System 2003 (Abstract)

Keef, K.D., Murray, D.C., Sanders, K.M. and Smith, T.K. (1997). Basal release of nitric oxide induces an oscillatory motor pattern in canine colon. J. Physiol. (Lond) 499: 773-786.

Keller, G.M. (1995). In vitro differentiation of embryonic stem cells. Curr. Opin. Cell Biol. 7: 862-869.

Kobayashi, S., Chowdhury, J.U., Tokuno, H., Nahar, S. and Iino, S. (1996). A smooth muscle nodule producing 10-12 cycles/min regular contractions at the mesenteric border of the pacemaker area in the guinea-pig colon. Arch. Histol. Cytol. 59: 159-168.

Kobayashi, S., Torihashi, S., Iino, S., Pang, Y.W., Chowdhury, J.U. and Tomita, T. (1995). The inner sublayer of the circular muscle coat in the canine proximal colon: origins of spontaneous electrical and mechanical activity. Archiv. Histol. Cytol. 58: 45-63.

Kölbel, C.B., Holtmann, G., Mcroberts, J.A., Schöler, S., Aengenvoordt, P., Singer, M.V. and Mayer, E.A. (1998). Involvement of chloride channels in the receptor mediated activation of longitudinal colonic muscle. Neurogastroenterol. Mot. 10: 489-498.

Lee, J.C.F., Thuneberg, L., Berezin, I. and Huizinga, J.D. (1999). Generation of slow waves in membrane potential is an intrinsic property of interstitial cells of Cajal. Am. J. Physiol. 277: G409-423.

Liu, L.W.C., Thuneberg, L. and Huizinga, J.D. (1995). Cyclopiazonic acid, inhibiting the endoplasmic reticulum calcium pump, reduces the canine colonic pacemaker frequency. J. Pharmacol. Exp. Ther. 275: 1058-1068.

Maruyama, T., Kanaji, T., Nakade, S., Kanno, T. and Mikoshiba, K. (1997). 2APB, 2aminoethoxydiphenyl borate, a membrane-penetrable modulator of Ins $(1,4,5) \mathrm{P}_{3}$-induced $\mathrm{Ca}^{2+}$ release. J. Biochem. 122: 498-505.

Michelangeli, F., Ruiz, M.C., Fernandez, E. and Ciarrocchi, A. (1989). Role of $\mathrm{Ca}^{2+}$ in H+ transport by rabbit gastric glands studied with $\mathrm{A} 23187$ and BAPTA, an incorporated $\mathrm{Ca}^{2+}$ chelator. Biochim. Biophys. Acta 983: 82-90.

Nahar, N.S., Torihashi, S., Iino, S., Senda, T., Chowdhury, J.U. and Kobayashi, S. (1998). Special smooth muscle cells along the submucosal surface of the guinea pig colon with reference to its spontaneous contractions. Cell Tissue Res. 293: 143-154.

Nakagawa, T., Yamanouchi, M. Ueshima, S., Fujii, H., Nakajima, Y. and Takaki, M. (2003). Intestinal spontaneous electrical and mechanical activities in $\mathrm{W} / \mathrm{W}^{\mathrm{v}}$ mutant mice. Enteric Nervous System 2003 (Abstract)

Nakayama, S. and Torihashi S. (2002). Spontaneous rhythmicity in cultured cell clusters isolated from mouse small intestine. Jpn. J. Physiol. 52: 217-227.

Nelson, M.T., Patlak, J.B., Worley, J.F. and Standen, N.B. (1990). Calcium channels, potassium channels, and voltage dependence of arterial smooth muscle tone. Am. J. Physiol. 259: C3-C18.

Niwa, H., Miyazaki, J. and Smith, A.G. (2000). Quantitative expression of Oct-3/4 defines differentiation, dedifferentiation or self-renewal of ES cells. Nat Genet 24: 372-376.

Plujà, L., Alberti, E., Fernandez, E., Mikkelsen, H.B., Thuneberg, L. and Jimenez, M. (2000). Evidence supporting presence of two pacemakers in rat colon. Am. J. Physiol. 281: G255-G266.

Robertson, E.J. (1987). Embryo-derived stem cell lines. In: Teratocarcinomas and Embryonic Stem Cells: 
A Practical Approach. ed. by E.J. Robertson 1st ed. Washington, DC: IRL Press, pp. 71-112.

Sanders, K.M. (1996). A case for interstitial cells of Cajal as pacemakers and mediators of neurotransmission in the gastrointestinal tract. Gastroenterol. 111: 492-515.

Sanders, K.M., Ördög, T., Koh, S.D., Torihashi, S. and Ward, S.M. (1999). Development and plasticity of interstitial cells of Cajal. Neurogastroenterol. Motil. 11: 311-338.

Sanders, K.M. and Smith, T.K. (1989). Electrophysiology of colonic smooth muscle. In: The Gastrointestinal System (Handbook of Physiology), ed. by S.G. Schultz and J.D. Wood American Physiological Society, Bethesda, MD, pp. 251-271.

Smith, T.K., Reed, J.B. and Sanders, K.M. (1987a). Origin and propagation of electrical slow waves in circular muscle of the canine proximal colon. Am. J. Physiol. 252: C215-C224.

Smith, T.K., Reed, J.B. and Sanders, K.M. (1987b). Interaction of two electrical pacemakers in the muscularis of the canine proximal colon. Am. J. Physiol. 252: C290-C299.

Suzuki H. (2000). Cellular mechanisms of myogenic activity in gastric smooth muscle. Jpn. J. Physiol. 50: 289-301.

Suzuki, H., Takano, H., Yamamoto, Y., Komuro, T., Saito, M., Kato, K. and Mikoshiba. K. (2000). Properties of gastric smooth muscles obtained from mice which lack inositol triphosphate receptor. J. Physiol. (Lond.) 525: 105-111.

Takaki, M. and Yoneda, S. (2003). The interrelation between spontaneous electrical activities and spontaneous longitudinal and circular muscle contractions in the mouse proximal colon. Enteric Nervous System 2003 (Abstract).

Takaki, M., Yoneda, S., Nakagawa, T. and Ishikawa, T. (2003). Role of interstitial cells of Cajal and enteric neurons on gut spontaneous motility. Auton. Neurosci.: Basic and Clinical 106: 41.

Thomsen, L., Robinson, T.L., Lee, J.C., Farraway, L.A., Hughes, M.J., Andrews, D.W. and Huizinga, J.D. (1998). Interstitial cells of Cajal generate a rhythmic pacemaker current. Nature Med. 4: 848851.

Torihashi, S., Fujimoto, T., Trost, C. and Nakayama, S. (2002). Calcium oscillation linked to pacemaking of interstitial cells of Cajal. J. Biol. Chem. 277: 19191-19197.

Torihashi, S., Ward, S.M. and Sanders, K.M. (1997). Development of c-Kit-positive cells and the onset of electrical rhythmicity in murine small intestine. Gastroenterol. 112: 144-155.

Uyama, Y., Imaizumi, Y. and Watanabe, M. (1992). Effects of cyclopiazonic acid, a novel Ca ${ }^{2+}$-ATPase inhibitor, on contractile responses in skinned ileal smooth muscle. Br. J. Pharmacol. 106: 208214.

Vanderwinden, J.M., Rumessen, J.J., Bernex, F., Schiffmann, S.N. and Panthier, J.J. (2000). Distribution and ultrastructure of interstitial cells of Cajal in the mouse colon, using antibodies to Kit and Kit (W-lacZ) mice. Cell Tissue Res. 302: 155-170.

Ward, S.M., Burns, A.J., Torihashi, S. and Sanders, K.M. (1994). Mutation of $c$ - kit blocks development of interstitial cells and electrical rhythmicity in the murine intestine. J. Physiol. (Lond.) 480: 9197.

Ward, S.M., Morris, G., Reese, L., Wang, X.Y. and Sanders, K.M. (1998). Interstitial cells of Cajal mediate enteric inhibitory neurotransmission in the lower esophageal and pyloric sphincters. Gastroenterol. 115: 314-329.

Ward, S.M., Ördög, T., Koh, S.D., Baker, S.A., Jun, J.Y., Amberg, G., Monaghan, K. and Sanders, K.M. (2000). Pacemaking in interstitial cells of Cajal depends upon calcium handling by endoplasmic reticulum and mitochondria. J. Physiol. (Lond.) 525: 355-361.

Yamada, T., Yoshikawa, M., Takaki M., Torihashi, S., Kato, Y., Nakajima, Y., Tsunoda, Y. (2002). In vitro functional gut-like organ formation from mouse embryonic stem cells. Stem Cells 20: 41-49.

Yamamoto, Y., Fukuta, H., Nakahira, Y. and Suzuki, H. (1998). Blockade by $18 \beta$-glycyrrhetinic acid of intercellular electrical coupling in guinea-pig arterioles. J. Physiol. (Lond.) 511: 501-508.

Yoneda, S., Kadowaki, M., Sugimori, S., Sekiguchi, F., Sunano, S., Fukui, F. and Takaki. M. (2001). 
Rhythmic spontaneous contractions in the rat proximal colon. Jpn. J. Physiol. 51: 717-723.

Yoneda, S., Takano, H., Takaki, M. and Suzuki, H. (2002a). Properties of spontaneously active cells distributed in the submucosal layer of mouse proximal colon. J. Physiol. (Lond.) 542: 887-897.

Yoneda, S., Kadowaki, M. and Takaki M. (2002b). Are interstitial cells of Cajal in submucosal layer pacemaker of the mouse proximal colon? Jpn. J. Physiol. Suppl. 52: 229.

Yoneda, S., Takano, H., Takaki, M. and Suzuki H. (2003). Effects of nifedipine and nickel ions on plateau potentials generated in submucosal interstitial cells distributed in the mouse proximal colon. $J$. Smooth Muscle Res. 39: 55-63.

(Received August 27, 2003; Accepted September 5, 2003) 